\title{
M-Pesa and its Perceived Effect on Performance of Manufacturing Firms: A Case Study of Thika Town in Kenya
}

\author{
Lucy Maina Kiganane \\ Nairobi, Kenya. \\ Teresia Ngina Kyalo \\ Nairobi, Kenya,
}

\begin{abstract}
During the last decade great expansion of information and communication technologies has taken place and indeed set the stage for a new era of entrepreneurial opportunities and challenges worldwide. However, very little has been done to assess the perceived effect of M-Pesa service on performance of manufacturing firms. This study sought to establish the perceived effect of M-Pesa mobile service on performance of manufacturing firms in Thika town in Kenya. A two-stage sampling technique was employed. In the first stage firms were divided into three groups (Small, Medium and Large) according to the number of employees. In the second stage simple random sampling technique was applied where each manufacturing firm from each category was given a serial number in its respective category and the numbers picked at random. A total of 120 questionnaires were self-administered yielding $100 \%$ response rate. Reliability and internal consistency of the measurement scale was tested using Cronbach's alpha. Analysis of Variance (ANOVA) was engaged to calculate the statistical significant differences between means. Post Hoc analysis was conducted using the Scheffe test to check the statistical significant differences between independent variables constituting the firm characteristics. Findings revealed that M-Pesa was frequently used and was perceived to have great positive effect on the performance of manufacturing firms. The location of the firm from the town Centre moderated the effect of M-PESA $2 \mathrm{kms}$ away from CBD. Results revealed that M-Pesa mobile phone service was perceived to have significantly increased sales volume, profit, worker productivity, and customer satisfaction ratings. These Results confirm that it is worth for firms to adopt and adapt to the new techno status quo resulting from entrepreneurial innovations in order to not only survive in the market but also attain a competitive edge.
\end{abstract}

Key Words:Innovation,Mpesa Mobile Phone Service, Manufacturing firm, Performance

\section{Background}

\section{INTRODUCTION}

Entrepreneurship and innovation are of fundamental importance to our economy as they spur economic growth and wealth creation (Barringer and Ireland, 2008).The dawn of wireless technology by innovative entrepreneurs has brought about many good changes including creating a new status quo in the processes, methods and operations of businesses, new products and services at the same time it has destroyed the old ways (status quo- disrupted the equilibrium) of business operations. Through the ages, firms have sought new opportunities that are critical in supporting their entrepreneurial activities and improve their position in the markets. Technology has indisputably been one of the most considerable contributors of good performance in business. The ever increasing development of technology leads firms to continually assess whether new technology is worth investing in and could possibly advance their business activities. .Firms would apply mobile phone technology to push performance to a higher level including customer satisfaction, cost savings, increased productivity, enhanced 
company image (Rangone\&Renga, 2006) and ultimately enhance the efficiency of business processes (Liang et al., 2007).

In Kenya the uptake of mobile phones has been unprecedented with $80 \%$ of Kenyan population now covered by Mobile networks. Kenya has seen a tremendous increase in the number of telephone subscriptions, from a Mobile subscription of: 23000 in 1995, 1187100 in 2002 which is $78.7 \%, 11,440,199$ in 2007 which amount to $97.7 \%$ of total telephone subscriptions respectively.Mobile Phone services have enhanced the value of a product or service in such a tremendous way. In general 'mobile' means "fully portable, real-time access to the same information, resources, and tools that, until recently, were available only from the desktop" (Shanker, O’Driscoll, and Reibstein, 2003).

Manufacturing Industry owes high pressure due to technological and competitive changes (Carlos et al., 2008). Strategies for enhancing competitiveness in manufacturing firms have become the need of the hour (Rao\&Soumya, 2007). The manufacturing sector in Kenya contributes around 13\% to GDP and this has remained largely unchanged since 1995 (Kenya Association of manufacturers, 2006).It is therefore a very critical sector in this error of economic recovery and transforming Kenya into an industrialized nation in the year 2030

M-Pesa (M for mobile, pesa is Swahili for money) is a mobile-phone based money transfer and micro-financing service, launched in 2007 by Vodafone for Safaricom and Vodacom, the largest mobile network operators in Kenya and Tanzania. Itis a small-value electronic payment and store of value system that is accessible from ordinarymobile phones.M-Pesa is a branchless banking service, meaning that it is designed to enable users to complete basic banking transactions without visiting a bank branch. The continuing success of M-Pesa in Kenya has been due to the creation of a highly popular, affordable payment service with only limited involvement of a bank.

M-Pesa customers can deposit and withdraw money from a network of agents that includes airtime resellers and retail outlets acting as banking agents. The service enables its users to: deposit and withdraw money, transfer money to other users and non-users, pay bills, purchase airtime and transfer money between the service and, in some markets like Kenya, a bank account A partnership with Kenya-based Equity Bank launched M-Kesho, a product usingMPesa's platform and agent network, that offers expanded banking services like interest-bearing accounts, loans, and insurance. It is termed the most successful of its type with over 18.1 million subscribers in Kenya and 78, 856 agents scattered all over the country, guaranteeing quick transactions.

\section{Statement of the problem}

The dawn of wireless technology by innovative entrepreneurs has brought about many good changes ( Created a new status quo) in the processes, methods and operations of businesses, new products and services at the same time it has destroyed the old ways (status quodisrupted the equilibrium) of business operations. Mobile phone services which are an entrepreneurial outcome and a constructive destruction technology have progressively rendered themselves in pervasive ways cutting across several manufacturing firms as well as other sectors of the economy (Vuolle, 2010).

In spite of the number of research studies carried out to establish the application of mobile phone services in firm operations (Matskin and Tveit, 2001; Lee 2001; Kannan 2001; Balasubramanian 2002). Very little has been done in exploring effect of application of M-Pesa phone service on performance of manufacturing firms. Contradictory and inadequate findings 
from previous studies have resulted from inconsistent definitions of ICT, different units of analysis, different-measures of Performance, limited theory base and dependence on crosssectional methods (Vuolle 2010).

Strategies for enhancing competitiveness in manufacturing firms have become the need of the hour (Rao\&Soumya, 2007).Manufacturing firms that have adopted the new technology (M-Pesa phone service) are thought to perform better than the rest. Firms have continued to invest large amounts of resources in M-Pesa phone services to align themselves with the current technology and adapt to the new techno status quo or else perish.Under the assumption that the process of creative destruction will lead to the eventual demise of some manufacturing firms that do not adapt to the new techno-status quo, what is the effect of M-Pesa in moving the manufacturing firms into the current techno-status quo as such reap maximum benefits ?A number of studies on the application of mobile phone services in firm operations have been published (Matskin and Tveit, 2001; Lee 2001).A few of these studies found no relationship between ICT services and firm performance. However quite a number of studies revealed that there is a strong positive relationship between use of mobile phone services and firm performance. Contradictory findings have therefore emerged from these studies. A clear picture of the relationship between ICT investment and firm performance had not emerged from previous studies.

Limited and contradictory findings have resulted from inconsistent definitions of ICT, different units of analysis, different-measures of Performance, limited theory base and reliance on crosssectional methods. Although there is a general notion in which mobile technologies can be applied in business, very little had been done in exploring the contribution of M-Pesa mobile Phone service in enhancing firm performance. This necessitated further research and the fact that more work on the same had been done outside Kenya constituted the need to study the Kenyan situation to see which side of the debate Kenyan results would fall. This study therefore sought to investigate the application of M-Pesa phone service on firm operations in Thika Town and probably provide an answer to the question as to "what is the perceived effect of M-Pesa on performance of manufacturing firms that have fully adopted this mobile phone service?"

\section{Introduction}

\section{LITERATURE REVIEW}

This chapter gives a systematic review of literature : First a critical review of the theoretical frameworks in entrepreneurship is presented followed by identification and presentation of the independent variables expected to influence performance and their relationship with the dependent variable illustrated by a conceptual framework

\section{Theoretical Framework}

This study squarely rests on Schumpeter's theory of disruptive innovation who emphasizes the process of "creative destruction" indicating how entrepreneurial innovations make current technology, products, processes, and services obsolete, and fuel economic activities for new products, services, technologies and processes. Disruptive Innovation implies that entrepreneurs are disruptive, disequilibrium force that plays aninnovative role in the market.

\section{The Disruptive Innovation Theory}

Disruptive innovation is a process by which a product or service usually created by a new entrant, with simple applications at the bottom of a market grows gradually and moves upmarket, and eventually displaces established competitors. It allows a new population of 
consumers' access to a product or service that would have been just accessible to markets with lots of money or skills. By focusing solely on sustaining innovations which historically has enabled them succeed, firms are making themselves vulnerable to - disruptive innovations. A firm which decides to ignore such entrepreneurial innovations which do not directly address the needs of their mainstream customers' risks catastrophic failure.The sustaining innovations are both the year-by-year incremental improvements that most companies develop but they are also the leapfrogging breakthrough innovations, for example the mobile phone services.

Disruptive approaches take advantage of competitor weaknesses and blind spots, and create differentiated, defensible growth strategies. Disruptive innovations offer 'good enough' performance and new benefits like simplicity, convenience or low prices. They appeal to customers or 'potential customers who may be looking for something different. The potential of disruptive innovation includes: Making the ugly attractive to overshot customers who don't value or use all of the benefits of existing products, providing cheaper, simpler or more convenient solutions, Scratching the unscratched itch by providing solutions and seizing new ways of doing things so as to make it easier and simpler to get business operations done, increase customer satisfaction, offer simple solutions that break bottlenecks, meet the tastes and preferences of customers and stay ahead of competition.

\section{Performance Measurement Models}

Various mobile technology evaluation models have been used for measuring the adoption usage intentions of mobile technologies and itseffects on performance including: Technology Acceptance Model (TAM), Task Technology Fit (TTF) model and the information systems (IS) Success Model (Vuoelle, 2011).

\section{Technology Acceptance Model}

This measurement model predicts user intentions through perceived usefulness and ease of use. Usefulness is conceptually related to performance and productivity (Gabauer, 2008; Bouwman\& van de Wijngaert, 2009).Perceived usefulness is the degree a person believes that using a particular system would enhance his or her job performance. Perceived usefulness is measured using statements concerning how using mobile phone service would enable workers to accomplish tasks more quickly, improve job performance enhance effectiveness of on the job, make it easier to do the job and how the worker would find technology useful in his/her job. Kim 2008 examines employee's intention to use mobile phone services due to perceived cost saving implying user's perception on smart phones provide cost effective communication and information exchange in terms of monetary factors, time and emotional effort.

\section{Technology satisfaction model}

Technology Satisfaction Model (TSM) is influenced by perceived usefulness and ease of use. Perceived market performance (profitability and revenue) is included as an organization level performance. There was a relationship between perceived usefulness and perceived market performance. Task -Technology Fit is used when examining mobile technologies in the work context (Lee et al., 2005); Gabauer, 2008). It measures how well the technology assists an individual in performing his or her work tasks. Performance here is measured using statements. Operational impacts refer to improving employee productivity and operational efficiency (Vuolle, 2010).Yuanet al., (2010) apply TTF to construct a mobile task model for identifying the fit between mobile task characteristic (mobility, location dependency and time critically) and mobile work support functions (location tracking,navigation,notification, and online job dispatching). 


\section{Conceptual Framework}

In the conceptual framework the pertinent independent variable M-Pesa,mobile phone service expected to influence the dependent variable - performance was identified. This was done taking into account that their causal relationship could be moderated by some firm characteristics. This study sought to establishthe perceived effect of M-Pesa, mobile phone service on firm Performance.

The conceptual mobile phone services value framework (figure2.3) shows the perceived relationship betweenM-Pesa, mobile services index (independent variables) and firm performance(dependent variable). Firm characteristics associated with stronger positive relationships between Mpesa mobile phone service and firm performance were considered as moderating variables.

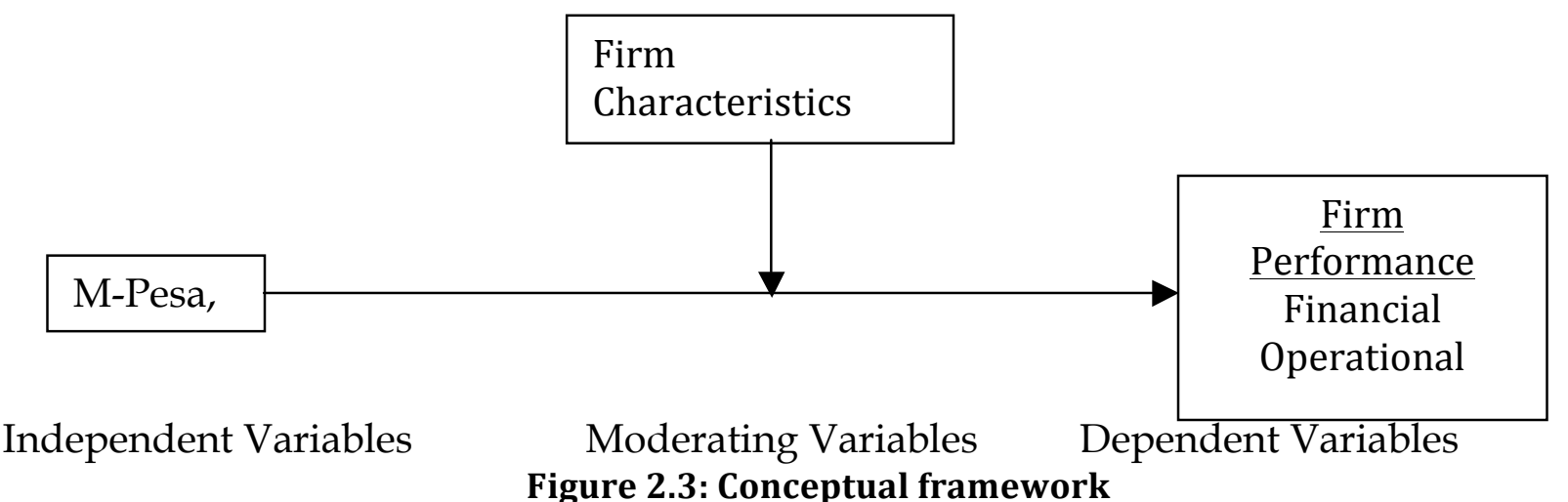

\section{Empirical Review Information Communication Technology}

The relationship between ICT and firm performance has long been debated for the last three decades. Empirical studies published since 1990s have convincingly argued that that ICT is a general purpose technology that facilitates entrepreneurial innovations.Since 1995 the acceleration in the growth rate of output and labour productivity can be traced for a large fraction to the advances in Information and Communication Technology .ICT stimulates entrepreneurial innovation as it encourages the creation and development of new ideas, products, and services. Firms that have introduced ICT have also in a parallel process or as a result of the introduction of ICT changed their internal organisation, among other things to make the organisation more flexible.

\section{Mobile Phone Services}

A mobile phone is an important ICT tool for development due to its ability to easily leapfrog the infrastructure barriers in remote and rural areas in Africa. The wireless industry is one of the most dynamic and growing industry in the world economy today. According to Bwisa (2010), the rapid technological advancement that the world has witnessed in the recent years especially in the electronic industry has also changed the means of production around the world. He reckoned that this can be evidenced in the telecommunication sector where, since the introduction and evolution of the mobile phones, the ways and means of business information transfer have changed leading to more efficiency and productivity in both service and manufacturing sectors. The rapid advancement in technologies and ease of use, coupled with the falling prices of devices, present the mobile phone as an appropriate and adaptable tool to bridge the digital divide (UN, 2009).Mobile services have special characteristics that are 
related to mobile work use, including task, technology and varying mobile use contexts (Yuan et al., 2010; Gebauer et al., 2010).

Mobile phones have an especially dramatic effect in developing countries substituting for scarce fixed connections (Waverman et al., 2005). M-Pesa remittanceis one of the key mobile phone services in Kenya.The uptake of mobile phones in Kenya has been unprecedented evidenced by about $80 \%$ of Kenyan population now covered by mobile networks. Kenya has seen a tremendous increase in the number of telephone subscriptions, from a mobile subscription of: 23000 in 1995, $1187100(78.7 \%$,) in 2002 and 11,440,199(97.7\%) in 2007. Mobile services enhance the value of a product or service.

Mobile services play a wide range of roles in an enterprise with varying effects on productivity, profitability, and processes (Baez et al., 2010). The flexibility of mobile phone technology makes it a very relevant business tool for all types of enterprises. According to Kelly, 2009, $84 \%$ of respondents in a survey of 100,000 individuals across 34 countries see the introduction of mobile technology as making their productivity either better or much better. Mobile communication and connectivity is said to improve efficiency in business operations and generate cost and time saving.

\section{The effect of M-Pesa,mobile phone service on financial sector}

In March 2007, Safaricom mobile operator launched M-Pesa the mobile money transfer system. It has since then become a popular mobile payment system with both the banked and the unbanked Kenyan population. This is one of the most recent developments which hasrevolutionized the mode of conducting business in Kenya. This service was widely used for receiving payments from customers (41.7\%), paying suppliers for orders $(12.8 \%)$, paying the employees' salaries/ wages (4.2\%), and bills payment among others. This is one of the services that were widely used by manufacturing firms for purposes of money transfer and receipt.

Mobile networks in Kenya offer m-money services in the name of M-Pesa by Safaricom, Orange money by Orange, Yu-cash by Essar, and Airtel money by Airtel. Currently the mobile money market size is about 15 million users transferring Kshs. 2 billion daily, of these over 14 million are M-Pesa customers. M-money providers have partnered with commercial banks such as Equity Bank, I\&M Bank, and Kenya Commercial Bank, Barclays and Co-operative to offer mobile based financial products that aim to reach the unbanked. M-Pesa service take a variety of shapes and serve three main purposes: mobile payments, mobile moneytransfers and mobile banking (Figure 2.5). Depending on the environment, these services can be championed by financial institutions,mobile network operators or third parties, such as platform developers, money transfer companies or NGOs (Baez, et al., 2010).The prevalence ofM-Pesa mobile technology has made mobile phones and networks a natural platform for addressing theshortcomings of traditional banking in Africa and other emerging markets. As can be seen inthe figure below M-Pesa mobile phone service has made financial transactions a lot easier and convenient. 


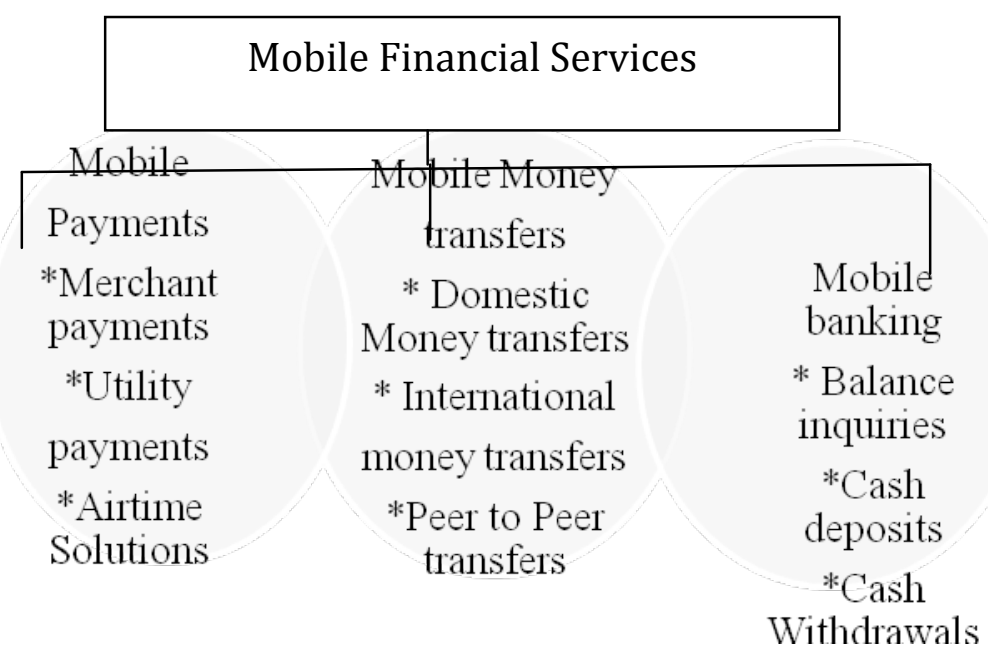

Source: Pyramid Research, 2009.

Figure2.5 Overview of mobile financial services

\section{Research Design}

\section{METHODOLOGY}

Exploratory research design with both descriptive and inferential analysis was adopted. To determine the relationship betweenM-Pesamobile phone services and firm performance both qualitative and quantitative research approaches were employed. Accurate, valid and reliable conclusions were drawn by engaging descriptive and inferential statistics. To ensure a more complete approach to empirical research data on firm performance of 120 manufacturing firms was examined. In this case data was collected retrospectively and reported for three consecutive years (Yin, 2009).

Technology Acceptance Model (TAM) which predicts Mpesa mobile phone service user intentions through perceived usefulness and ease of use conceptually related to performance and productivity (Gabauer, 2008; Bouwman\& van de Wijngaert, 2009) was applied. Technology satisfaction model (TSM) was also used to measures how well M-Pesa mobile phone service assists an individual in performing his or her work tasks and the level of profitability as well as business income.

\section{Population}

The target population was a total of 200 manufacturing firms comprising all Small, Medium and Large manufacturing firms in Thika town that had been in operation for at least three years.

\section{Sampling Frame and Technique}

Thesampling frame was drawn from Thika Municipal Council Business Register dated 27th January, 2011 with a total of approximately 200 manufacturing firms. In this study the formula for determining the sample size and a procedure for categorizing data (Cochran, 1977) was adopted. The sample size was calculated using the following Formula:

$e=Z_{\alpha} \sqrt{\frac{p q}{n}}$. This is simplified ton $=\frac{z_{\alpha}^{2} p q}{s^{2}}$, where $q=1-p$.

$\mathrm{n}=$ The sample size required 
$z_{\alpha}=$ Confidence Level at 95\% (standard normal value at $\alpha$ level of significance of 1.96)

$\mathrm{p}=$ Estimated Mpesa Mobile phone service users

$\mathrm{e}=$ Margin of error at $5 \%$ (standard value of 0.05 )

With thoroughly estimated mobile phone usage of between $70 \%$ and $80 \%$, paws assumed to be $75 \% \pm 5 \%$ that is $p=0.75 \pm 0.05$.

Given that $\alpha=0.05, Z_{\alpha}=1.96$ ande $=0.05 n=\frac{1.96^{2} \times 0.75 \times 0.25}{0.05^{2}}$

$$
n=288.12 \text { Approximately } n=288
$$

This is the representative sample size for an infinite population but in this study the sampling frame of manufacturing firms in Thika town as per the list obtained from Thika Municipal Council Business Register dated 27th January 2011, was 200.

Since $\mathrm{N}$ is finite the researcher adjusted the sample using the formula:

$$
\begin{array}{ll} 
& =\frac{\mathrm{n}_{0} \mathrm{~N}}{N+n_{0}} \\
& =\frac{288 \times 200}{288+200} \\
n=118.05 & n \geq 118
\end{array}
$$

Using the standard values and formula provided above a sample of at least 118 manufacturing firms was representative.

A two-stage sampling technique was employed. In the first stage firms were stratified into three groups (Small, Medium and Large) according to the number of employees, that is, Small firms employing between 1-49 employees, Medium firms employing between 50-99 people and large firms employing 100 and above. In the second stage simple random sampling technique was applied where each manufacturing firm from each group was given a serial number in its respective category and the numbers picked at random. The total number of large manufacturing firms was approximately 14; Medium was approximately 34 and small was approximately 72 . The sample size was therefore 120 in the ratio: 3:7:15 representing Large, Medium and small manufacturing firms respectively.

\section{Research Instruments and Data Collection Procedure}

Data was collected by use of a structured questionnaire. It was the preferred research instrument since it has the potential to gather data over a large sample and translate the research objectives into specific questions and answers as well as provide the necessary data for hypothesis testing. Observation was also applied for triangulation purpose.

The questionnaire constituted four parts: Part I contained questions on the background of the firm, Part II constituted questions on the perceived usage of M-Pesa mobile phone services in the firms, Part III contained questions on measuring performance and a 5 point Likert scale of 1-strongly disagree, 2-disagree, 3-Neutral, 4-Agree and 5- Strongly Agree examining the perceived effect of Mpesa mobile phone services on firm performance.The Questionnaire was self-administered with the help of research assistants to the 120 manufacturing firms which had been in operation for a minimum of three years.

\section{Data Processing and Analysis}

For accurate analysis the data was first coded and entered into SPSS. Data cleaning and variable aggregation to come up with the M-Pesa mobile phone service index was undertaken. Transformation of some variables was then done through existing tools in SPSS. Descriptive and inferential analysis was adopted. 
Descriptive Statistical Analysis include use of frequencies, percentages, measures of central tendency, measures of dispersion, graphs, tables and figures were usedin addition to descriptive analysis of the responses on statements used for measuring perceived usefulness and ease of use of Mpesa mobile phone services using Technology acceptance and Technology satisfaction models.Inferential Statistical Analysisincluded: One-way sample t-test, One-way ANOVA, Scheffe's test, Correlations.

\section{Measurement of Performance}

The dependent variable (performance) was measured using TAM, TSM. Technology Acceptance Model (TAM) is a measurement model which predicts user intentions through perceived usefulness and ease of use. Usefulness is conceptually related to performance and productivity (Gabauer, 2008; Bouwman\& van de Wijngaert, 2009).Perceived usefulness is the degree a person believes that using a particular system would enhance his or her job performance. Perceived usefulness is measured using statements concerning how using MPesamobile phone service would enable worker to accomplish tasks, enhance customer satisfaction, improve firm operations, enhance effectiveness, make it easier to do the job and how the worker would find technology useful in his/her job.

Technology Satisfaction Modelis influenced by perceived usefulness and ease of use. Perceived market performance (profitability and revenue) is included as an organization level performance. It measures how well the technology assists an individual in performing his or her work tasks and the level of profitability as well as business income. Performance here is measured using two statements: Firms profitability has greatly increased since the adoption and use of Mpesa mobile phone Service. Since the adoption and usage of Mpesa mobile phone service there has been increasing worker productivity and responsiveness

\section{Research Findings}

\section{RESEARCH FINDINGS AND DISCUSSION}

The research informally gathered thatM-Pesa mobile phone service is widely used by most manufacturing firms. In a sample of ten firms, at least seven were found to be using M-Pesa mobile phone service in their day to day operations. The proportion of manufacturing firms using theM-Pesa mobile phone service was estimated to be $(75 \%)$.

The study response rate was $100 \%$ which was highly significant and a reasonable representation of the sample and indeed the entire Population.To determine the usage ofMPesa mobile phone service the study also analyzed ways in which owners of manufacturing firms use M-Pesa mobile phone service to serve customers, suppliers, employees and others.

One- Sample T-test was used to determine the application of M-Pesa mobile phone service on firm operations and approve or disapprove the null hypothesis $\mathrm{H}_{0 \mathrm{i}}$ : The perceived positive influence of M-Pesa mobile phone service on business performance is not significantly different from zero. Qualitative data for each variable was collected from each firm in the sample using a five point Likert scale ( $1=$ strongly disagree, $2=$ disagree, $3=$ Neutral, $4=a g r e e$, $5=$ strongly agree) to find out the level of influence of M-Pesa mobile phone service on the Performance of small, medium and large manufacturing firms. In this case the test value $(\mathrm{t})$ is 3 which is the point of reference, the neutral value or the "Zero" value. If the value of $t$ wasabove 3 , the null hypothesis was rejected. On the other hand a t-value of below 3 implies that the null hypothesis was accepted. 
The Cronbach's alpha analysis for M-Pesa gave a value of 0.828 which is significantly high indicating a strong internal consistency among the measures of performance items. The fact that M-Pesa alpha value is high makes it possible to predict scores from one measure of performance. On effect of M-Pesa on performance, One Sample t-test revealed that the effect is significantly different from $0(t=10.827, p<0.001)$ leading to rejection of the null hypothesis. This implies that the perception of the respondents is that M-Pesa has a significant effect on the performance of manufacturing firms.

\section{Discussion of findings}

According to Smith (2006), m-commerce is considered a pull market as reflected in increasingly positive attitudes towards the implication of such technology into routine decision-making tasks. The study indicates that receiving of payments from customers was very critical in terms of money transfer as reflected by $42 \%$ of respondents. This finding is in tandem with the finding of Haaker et al (2006) who indicate that targeting, branding in the service domain, and revenue sharing in the finance domain were vital aspects in mobile commerce.

Previous research findings revealed that convenience of the money transfer technology plus its accessibility, cost, and support factors are related to actual usage of the mobile payment services by the micro businesses to enhance their success and growth( Mbogo, 2010). This is consistent with the findings of this study which revealed that $85.7 \%$ of the respondents felt that usage of M-Pesa was critical to the long-term success of a firm since ithad a positive effect on the performance of the firms.

In this study $70.9 \%$ respondents confirmed that M-Pesa was often used in most firms as the most efficient tool for money transfer. This strongly tallies with the revelation from previous study that this mode of payment is an easier form of cash delivery to the suppliers and business partners, a system which is relatively affordable, personal and can be used anywhere and at any time (Anurag, Tyagi and Raddi, 2009).

Studies has revealed that the micro-business operators are able to transact payments directly with their customers and suppliers through a mobile phone in the palm of their hands without necessarily going through a bank and without having to leave their business premises. This is beneficial because all it requires is for one to have a mobile phone and basic literacy to operate the phone. In concurrence, this study indicates thatMpesa mobile phone service is widely used by customers to make payments (3.2\%) by and to suppliers. Omwansa, (2009) in his study reckoned thatmany unbanked Kenyans can now receive or send money wherever they are in the country.

\section{SUMMARY AND CONCLUSION}

The technological basedM-Pesa mobile phone service has enabled entrepreneurs to model andlaunch new functionalities that seem to have provided life changing solutions to not only the manufacturing firms but also other businesses. This study sought to explore the perceived influence of Mpesa mobile phone service on firm performance. A sample of 120 manufacturing firms was used of which more than $78 \%$ had been in operation for more than three years. The study's response rate was $100 \%$ which was highly significant and a reasonable representation of the sample and indeed the entire population.

Results reveal that of the 120 sample of manufacturing firms studied, $85 \%$ of the firms engage in product business while $40.8 \%$ engaged in service business -This is a total of $125.8 \%$. The results therefore indicate that $25.8 \%$ deal in both products and services. In a sample of ten 
firms, at least seven were found to be using M-Pesa phone service in their day to day operations. The proportion of manufacturing firms using theM-Pesa mobile phone service was $75 \%$. This study revealed that manufacturing industry is male dominated with $80.8 \%$ of firms owned by men whereas only $19.2 \%$ were owned by women. It further revealed that $85 \%$ of the respondents had attained secondary education and above whereas a significant $10 \%$ of the respondents had no formal education.

Some entrepreneurs confessed thatM-Pesa service was "God sent" It was the core of their businesses which was widely used for receiving payments from customers $(41.7 \%)$, paying suppliers for orders (12.8\%), paying the employees' salaries/ wages (4.2\%), and bills payment among others. This is one of the services that is widely used by manufacturing firms for purposes of money transfer and receipt.

\section{References}

Anurag, S., et al., (2009). "Mobile Payment 2.0: The Next-Generation Model HSBC"s Guide to cash, Supply Chain and Treasury Management in Asia Pacific.Ed.178

Baez G.; KechicheB. ;\&Boguszewska S.(2010). Services In Nigeria: How Mobile Technologies Are Transforming Economic And Social Activities. Canal Park Cambridge, USA

Barringer, B.R. \& Ireland, R.D. (2008).Entrepreneurship: Successfully launching new ventures, Pearson Prentice Hall.

Bwisa, H. (2010).An Entrepreneurship Approach to use of ICT for Growth of Africa's Corporative movement: The case of the mobile phone. A concept paper, Swaziland.

Carlos F. et al., (2008). "Project management in the context of organizational change: the case of the Portuguese public sector public sector", International journal of public sector management, Vol2/No.6, pp. 573-85

Cochran, W.G. (1977). Sampling Techniques (3 Ed). New York: John Wiley \& Sons.

Gebauer, J., and Shaw, M.J., and Gribbins, M.L. (2010) "Task-technology fit for mobile information systems", Journal of Information Technology, Vol. 25, pp.259-272.

Gebauer, J. (2008) "User requirements of mobile technology: A summary of research results", Information Knowledge Systems Management, Vol. 7. No. 1/2, pp. 101-119.

Haakeret. al. (2006).Consumer value of context Aware and location Based Mobile Services. Twenty first Bled conference, e-collaboration on overcoming boundaries through multi-channel interaction.

Lee, T.M. and Park, C. (2008) "Mobile technology usage and B2B market performance under mandatory adoption", Industrial Marketing Management, Vol. 37, No. 7, pp.833-840.

Liang, T-P.Huang, C-W., Yeh, Y-H.and Lin, B. (2007) "Adoption of mobile technology in business: a fit-viability model”, Industrial Management \& Data Systems, Vol. 107, No. 8, pp. 1154-1169.

Matskin, M. and Tveit, A. (2001).Lee, R. 2001; Kannan, P. et al; 2001.Balasubramanian, S. et. al, 2002). Exploring the implication of M-commerce for markets and marketing. Journal of the Academy of marketing science, Vol.30 No.4.

Omwansa, T. (2009). "M-Pesa progress and prospects": Innovations case discussion. http://www.strathmore.edu/pdf/innov-gsma-omwansa.pdf > Accessed 28 $8^{\text {th }}$ April, 2009.

Rao, S. and Soumya, K. J. (2007).Strategies for enhancing competitiveness of firms, Industrysectors and Country. Institute of management studies \& Research, Mumbai.

Rangone, A. and Renga, F. (2006) "B2B mobile internet: an exploratory study of Italian applications", Business Process Management Journal, Vol. 12, No. 3, pp. 330-343.

Shanker, V. O’Driscoll, T. and Reibstein, D. (2003).Rational Exuberance: The Wireless Industry Killer B, Strategy and Business Vol.31.

Smith, A. (2006). International Journal of Mobile Communications, Vol. 4 Issue 6

UN, (2009).Mobile Commerce in Africa. An overview with specific reference to South Africa, Kenya and Senegal.

First Session of the Committee on Development Information Science and Technology. Addis Ababa, Ethiopia. 
Vuolle, M. \&Kapyla, J. (2010) “Theoretical Evaluation Models Used in Mobile Work Context”, the Proceedings of the Ninth International Conference on Mobile Business/Ninth Global Mobility Roundtable, Athens, Greece, June 13-15 2010, pp. 425-431.

Waverman, L. et al., (2005). The impact of telecoms on economic growth in developing countries in Africa: The Impact of Mobile Phones: Moving the Debate Forward, The Vodafone Policy paper series, No.2

Yin, R.K. (2009). Case study research: Design and Methods. Fourth edition, Applied social research methods series, Vol. 5, Sage Publications, Inc. 219 p.

Yuan, Y., Archer, N., Connelly, C.E., and Zheng, W. (2010).Identifying ideal fit between mobile work and mobile work support, Information \& Management, Vol. 47, No. 3, pp. 125-137. 